\title{
VARIAÇÃO ESTACIONAL DA COMPOSIÇÃo CENTESIMAL DO PEIXE DE ÁGUA DOCE, Pimelodus clarias BLOCH (MANDI)*
}

\author{
MARÍLIA OETTERER DE ANDRADE** \\ URGEL DE ALMEIDA LIMA***
}

\section{RESUMO}

O presente trabalho teve por objetivo verificar a variação, com a época de captura, na composição em umidade, proteína, lípides e cinza da carne do peixe, a fim de se conhecer quais os meses em que o mandi se presta melhor ao aproveitamento tecnológico.

Foi verificado que a composição centesimal varia durante o ano e como média para os 12 meses encontrou-se: $65,15 \mathrm{~g} / 100 \mathrm{~g}$ de umidade, $17,92 \mathrm{~g} / 100 \mathrm{~g}$ de proteina, $15,51 \mathrm{~g} / 100 \mathrm{~g}$ de lípides e $1,34 \mathrm{~g} / 100 \mathrm{~g} \mathrm{de}$ cinza. O mandi é peixe gordo e os meses escolhidos para a captura dos peixes destinados ao processamento foram os de junho e julho.

\section{INTRODUÇÃO}

A determinação da composição química dos peixes, segundo LOVE (1957), exige técnica apurada uma vez que os dados analíticos variam grandemente de acordo com a idade, com o sexo e com a estação do ano, tendo, portanto, significado apenas para um determinado lote de peixes. $O$ autor afirma que das 2.000 espécies de peixes conhecidos, apenas 300 ou 400 foram analisadas, na maioria marinhas.

Para GEIGER (1962), o teor de proteína de peixes varia com o teor de umidade, o que não afeta a qualidade nutricional do peixe; é desejável, portanto, que se expresse o teor protéico dos peixes em termos de porcentagem de matéria seca. $\mathrm{O}$ autor explica a necessidade de se analisar o peixe inteiro porque as diferentes partes podem ter diferentes teores de proteína. Podem ocorrer variações conforme o tipo de carne, sendo que a carne branca contém menos proteína e mais lípides, quando comparada com a carne escura de um mesmo peixe.

De acordo com JACQUOT (1961), os fatores que afetam a composição química de peixes são numerosos, sendo alguns de natureza intrínseca tais como os fatores genéticos, morfológicos e fisiológicos; ou como os fatores ambientais, isto é, relativos às condições de vida e, particularmente, de alimentação. $O$ autor mostra os teores variáveis em umidade, proteína, lípides e cinza encontrados em espécies diferentes, em indivíduos dentro de uma espécie, em partes dos peixes, em sexo e estágio de desenvol-

* Entregue para publicação em 29/12/1975. Parte da Tese de Mestrado apresentada pela autora ANDRADE, M.O. (1975) para a obtenção do título de Mestre em Ciência dos Alimentos na Faculdade de Ciências Farmacêuticas da USP.

* Bolsista da FAPESP.

*** Departamento de Tecnologia Rural da ESALQ. 
vimento ou maturação. $\mathrm{O}$ autor ainda classifica as espécies de peixes em gordos, semigordos e magros, de acordo com a composição apresentada como segue: peixes gordos: $68,6 \%$ de umidade, $20,0 \%$ de proteína, $10,0 \%$ de lípides e $1,4 \%$ de cinza; peixes semigordos: $77,2 \%$ de umidade, $19,0 \%$ de proteína, $2,5 \%$ de lipides e $1,3 \%$ de cinza; peixes magros: $81,8 \%$ de umidade, $16,4 \%$ de proteina, $0,5 \%$ de lípides e $1,3 \%$ de cinza.

NOTEVARP (1950) analisou arenques noruegueses; encontrou variações nos teores de proteína, lípides, alguns minerais e algumas vitaminas justificando essas variações como sendo consequiência do local de captura, estação do ano, espécie, tamanho e maturidade dos peixes. A evidência dessa afirmação está nos resultados obtidos pelo autor e citados em seguida, respectivamente, para proteína e lípides em g/100 g, para cálcio e fósforo inorgânico em mg/100 g e para vitamina A em U.I./100 g. Em a renque de inverno foram encontrados: 17 a $18 ; 12$ a $15 ; 100 ; 270$ e 400 . Em arenque de primavera: 17 a $18 ; 8$ a $12 ; 100 ; 250$ e 400 . Em arenque gordo: 17 a $18 ; 8$ a $20 ; 40 ; 250$ e 400. Em arenque pequeno: 16 a $17 ; 3$ a $15 ; 40 ; 200$ e 400 .

RULEV \& MAKAROVA (1959) verificaram que os teores de umidade, proteina e lípides do arenque do Atlântico (Clupea harengus) analisado inteiro, variam com os meses do ano. $O$ teor de lípides em março é de 11 a $13 \%$, em abril é de 4 a $6 \%$, em junho é de 13 a 14\%, em agosto de 18 a 23\%, no começo de novembro de 14 a $15 \%$, e no fim de novembro de 12 a 14\%. Os autores afirmam que estas variações em lípides são possíveis durante vários anos. $O$ teor de proteína se manteve entre $16 \%$ e $19 \%$. $O$ teor de umidade em abril e maio varia de 70 a $74 \%$, quando os lípides são baixos e depois diminui nos meses restantes chegando a ser de 58 a $65 \%$.

FERREIRA (1951) analisou sardinhas (Clupea pilchardus), "jurel" (Trachurus trachurus) e merluzas (Merluccius meriuccius) e encontrou os resultados indicados a seguir, respectivamente, para umidade, proteína, lípides e cinza, expressos em porcentagem. Em sardinha de primavera: 67,$4 ; 27,3 ; 2,0$ e 2,1 . Em sardinha de verão-outono: 64,$3 ; 24,0 ; 8,6$ e 2,1 . Em sardinha de inverno: 66,$4 ; 24,9 ; 6,8$ e 2,6. Em "jurel": 75,9 ; 20,$5 ; 1,8$ e 1,4 . Em merluza: 80,$4 ; 17,0 ; 0,7$ e 1,2 .

ITÔ et alii (1969), estudaram a variação estacional e gonadal da composição química das sardinhas (Sardinella aurita), capturadas nas águas do Oceano Atlântico, em Santos. Os autores obtiveram como média de 4 anos de análise: $72,5 \%$ de umidade, $21,9 \%$ de proteína, $4,6 \%$ de lípides, $2,0 \%$ de cinza, $49,9 \mathrm{mg} / 100 \mathrm{~g}$ de cálcio e 76,1 $\mathrm{mg} / 100 \mathrm{~g}$ de magnésio.

A composição química da corvina (Micropogon furnieri) e da pescada-foguete (Macrodon ancylodon), capturadas nas águas do Oceano Atlântico, no Estado do Rio Grande do Sul, foi determinada por ITÓ \& WATANABE (1968) e os resultados médios para cada um dos peixes foi o seguinte: 79,8 e $80,1 \%$ de umidade; 20,2 e $18,4 \%$ de proteína; 1,9 e $2,1 \%$ de lípides; 1,2 e 1,2\% de cinza; 41,5 e $19,2 \mathrm{mg} / 100$ de cálcio; 1,7 e $1,2 \mathrm{mg} / 100 \mathrm{~g}$ de ferro; $98,6 \mathrm{e} 155,9 \mathrm{mg} / 100 \mathrm{~g}$ de fósforo inorgânico e 38,7 e 36,6 $\mathrm{mg} / 100 \mathrm{~g}$ de magnésio.

Alguns componentes químicos de nove espécies de peixes de mar das Costas da Åfrica foram analisadas por WAGENKNECHT \& LANGECKER (1969) que encontra- 
ram de 16,6 a $23,0 \%$ de proteína e de 0,5 a $13,3 \%$ de lípides. O valor calórico foi de 83 a $175 \mathrm{kcal} / 100 \mathrm{~g}$ de peso úmido.

THURSTON (1961) determinou a composição centesimal e os teores de sódio e potássio, de quatro espécies de peixes. Para o Sebastodes alutus, para o bacalhau (Gadus morrhua) e para o "ling cod" (Ophiodon elongatus) encontrou os seguintes resultados: a umidade variou de 79,0 a $81,0 \%$, a proteína de 18,0 a $19,0 \%$, os lípides de 0,5 a $1,5 \%$, a cinza de 1,1 a $1,3 \%$, o sódio de 60 a $70 \mathrm{mg} / 100 \mathrm{~g}$ e o potássio de 390 a $440 \mathrm{mg} / 100 \mathrm{~g}$. Para o "sablefish" (Anoplopoma fimbria) a umidade foi de $71 \%$, a proteína de $13 \%$, os lípides de $15 \%$, a cinza de $1 \%$, o sódio de $56 \mathrm{mg} / 100 \mathrm{~g}$ e o potássio de $348 \mathrm{mg} / 100 \mathrm{~g}$.

O valor nutritivo de dois tipos de perca do mar (Sebastus marinus e Sebastus mentilla) e três tipos de solha (Platessa platessa, Hippoglossoides platissoides e Limanda limanda) foi estudado por KHOBOTILOVA (1967). A carne de ambas as percas do mar apresentou aproximadamente $17,5 \%$ de proteína e 2,0 a $10,0 \%$ de lípides, enquanto que as solhas continham de 15 a $17 \%$ de proteína e de 1 a $7 \%$ de lípides. $O$ autor afirma que os peixes estudados se prestam à produção de defumados de alta qualidade.

Os teores de umidade, proteína, lípides e componentes nitrogenados não protéicos foram determinados por DAMBERGS (1963) nos filés do bacalhau (Gadus morrhua). Após um ano de análise com 36 peixes de tamanho homogêneo (entre 56 e $61 \mathrm{~cm}$ ) os resultados foram $81,00 \%$ de umidade, $15,66 \%$ de proteina, $1,01 \%$ de lípides e $2,36 \%$ de componentes nitrogenados não protéicos. Os machos e fêmeas foram analisados indistintamente porque em uma análise prévia foi verificado que entre sexos havia apenas ligeiras diferenças na composição centesimal. $\mathrm{O}$ autor substituiu a determinação de proteína através do nitrogênio total por método gravimétrico, para evitar incorreções que pudessem ocorrer no primeiro pelo uso de controvertido fator de conversão 6,25 para 0 nitrogênio. Quanto aos lípides, ocorreu maior concentração destes na região próxima à cabeça do peixe.

Para LUDORFF (1963), os arenques apresentam variação na composição em termos de umidade, proteína, lípides, cloreto de sódio e variação no valor energético conforme o local de captura e época do ano. $\mathrm{O}$ autor apresenta resultados de análises de arenques, destacando essas variações nos peixes inteiros e nos filés. Os constituintes citados acima expressos em g/100 g e o valor calórico em kcal são indicados a seguir. Para o arenque alemão do Mar do Norte (julho a novembro) foram encontrados: $47 ; 13 ; 13$; 1 e 174. Para filés de arenque alemão do Mar do Norte: $63 ; 18 ; 18 ; 1$ e 241 . Para o arenque alemão do Báltico (janeiro a abril): $47 ; 12 ; 8 ; 0,4$ e 123 . Para filés de arenque alemão do Báltico: $70 ; 18 ; 12 ; 0,6$ e 186 . Para o arenque norueguês (fevereiro a junho): $46 ; 13 ; 10 ; 1$ e 146 . Para filés de arenque norueguês: $66 ; 18 ; 15 ; 1$ e 214.

Analisando trinta e uma espécies de peixes da Costa "Malagasy" a fim de determinar umidade, proteína e lípides, FRONTIER-ABOU (1970) encontrou valores médios de $77,46 \%$ de umidade; $20,34 \%$ de proteína e $0,83 \%$ de lípides. Os peixes eram magros e apenas três espécies apresentaram mais de $3 \%$ de lípides. O autor verificou que há relações significativas umidade-lípides em sete espécies, e umidade-nitrogênio em dezoito. As flutuações na composição dos peixes parece, segundo o autor, dever-se à substituição de uma parte da umidade de composição do tecido muscular por lípides e proteínas. $O$ 
autor afirma que é válido o uso do fator 6,25 para a estimativa da proteína com base no nitrogênio.

LOVE (1957) discute os métodos usados nas análises de proteínas, lípides e minerais em peixes. Com relação às proteínas, explica que apesar do fator de conversão mais aceito ser 6,25, alguns autores propõem o uso de 6,025 e até 5,72 para o salmão. Ainda, com relação à proteína, afirma que há defensores da determinação de nitrogênio isolando primeiro a proteina "pura" por precipitação com ácido tricloroacético. Para o autor, embora o método de extração de lípides em aparelho de Soxhlet seja universalmente o mais generalizado, pode não ser o melhor, principalmente para peixes mais magros onde a extração é maior ou menor segundo a escolha do solvente. Ainda, na determinação de lípides, há influência de inúmeros fatores como: técnica de filetagem, acúmulo de gordura nos peixes nas épocas de reprodução, desova em diferentes épocas do ano, mesmo dentro de uma mesma espécie, como ocorre com os arenques, e concentrações diferentes de lípides dentro do corpo do peixe, estando o maior volume logo abaixo da pele e na parte ventral. Nas determinações de cinza, os erros mais comuns segundo o autor, são devidos à inclusão da pele e da parte esquelética na amostragem e à participação dos elementos em mais de uma molécula complexa. Neste caso, os resultados não são os ideais como é o exemplo do fósforo que está presente nos fosfatos, nas fosfoprote ínas e nos ácidos nucléicos. A cinza dos peixes de rio decresce durante a migração para o mar $\epsilon$, nus peixes de lago, o teor cálcio nos tecidos é proporcional à porcentagem de cálcio na água.

De acordo com GEIGER (1962), o método de Kjeldahl, para determinação do teor de proteína em peixes, multiplicando o teor de nitrogênio por 6,25 , pode ser criticado apesar da maioria dos pesquisadores o usarem em experimentos de nutrição. A determinação de nitrogênio inclui outras frações que diferem nutricionalmente da proteína do músculo, como por exemplo a proteína tipo gelatina e outros extrativos, incluindo aminoácidos livres que não representam a proteina verdadeira.

Estudando quimeras (Hydrolagus affinis), esturjoes (Acipenser oxyrhynchus) e vários teleósteos, FRASER et alii (1961) verificaram que a composição da carne branca desses peixes é semeihante, com exceção dos lípides, os quais variam de $0,7 \%$ nos eglefins ("haddock") (Melanogrammus aeglefinus) a 12\% nas enguias (Notocanthus nasus). Nos eglefins a maior parte dos lípides situa-se na parte ventral; as faces laterais de coloração marrom desses peixes contém 2,0\% de lípides. Segundo esses mesmos autores, a proteína varia de 14,8 a $16,2 \%$ para a maioria das espécies, mas aparece em menor teor nos esturjões e nas quimeras, e em maior proporção na cavala, no atum e no hipoglosso.

MacCALLUM et alii (1969), durante vinte anos analisaram o "capelin" (Mallotus villosus), em sua atividade de migrar para as praias de Terranova para desova e notaram declínio do teor de lípides (mais evidente nos machos), aumento de umidade e pequeno decréscimo em proteína na época de migração. Em relação ao peso úmido, as faixas de variação foram: 8,1 a $1,8 \%, 77,0$ a $82,3 \%$ e 15,0 a $12,9 \%$ para lípides, umidade e proteína bruta, respectivamente. Quanto ao método de extração de lípides, os autores obtiveram melhores resultados com o uso de mistura de clorofórmio-metanol do que com éter ou benzeno. Com clorofórmio-metanol os valores chegaram a ser até $30 \%$ mais elevados nas análises de peixes que possuem menos de $3 \%$ de lípides. Segundo os autores, 
nos peixes analisados inteiros, o teor de proteína bruta é mais baixo do que nos filés (14\% "versus" $15 \%)$, devido à presença dos ossos e do colágeno.

GRISHINA \& KUZNETSOV (1974) utilizaram, para a extração dos lípides da carne de peixes, soluções de clorofórmio-etanol e o óleo extraído foi quantificado gravimetricamente. Os autores afirmam que este método, além de rápido, se adapta bem para a determinação dos lípides de bacalhau "in natura" e congelado, de "live pike", de peixes conservados, caviar e farinha de peixe.

LOVERN (1965) discute os métodos de extração de lípides em músculo de peixes "in natura" e em produtos elaborados de peixes, afirmando que ocorrem muitas variações nos resultados de extrações quantitativas de lípides apresentados por diferentes pesquisadores. $\mathrm{O}$ autor dá preferência ao uso de mais de um solvente como o clorofórmio-metanol capazes de liberar os lípides ligados em cadeia com proteínas, típicos do tecido animal: Contudo, explica que a proporção entre solventes deve ser perfeitamente mantida para evitar a contaminação do extrato com não-lípides e as perdas de lípides na camada de metanol.

STANSBY (1951) cita a variação estacional do teor de óleo encontrado na cavala, afirmando que ela encerra de $3,9 \%$ a $19,2 \%$ de lípides, os quais aumentam de abril a meados de agosto e decrescem até novembro, porém, com oscilações entre agosto e novembro. $\mathrm{O}$ autor estudou a correspondência do tamanho do peixe com a porcentagem de óleo e estimou o tamanho com a idade provável, concluindo que os peixes, conforme vão ficando mais velhos, ficam mais ricos em gordura. Além disso, o teor de lípides aumenta até quatro vezes aos cinco, seis anos de idade e, a partir daí, permanece quase sem variações de mês para mês.

BROOKE et alii (1962) determinaram os teores de umidade, proteína, lípides, cinza, sódio e potássio do "butterfish" (Poronotus triacanthus), da pescada-polaca (Pollachius virens), de duas espécies de merluzas e cinco espécies de solha. Os autores afirmam que a estação do ano em que os peixes foram capturados influi na composição centesimal dos filés e do peixe inteiro, principalmente, com relação aos teores de lípides. As análises dos peixes inteiros expressas em porcentagem, respectivamente, para umidade, lípides, proteína e cinza, revelaram para o "butterfish": 68,7 a 71,$9 ; 14,7$ a 15,$4 ; 8,4$ a 13,0 e 3,1 ; para as solhas: 74,2 a 80,$9 ; 14,1$ a 17,$2 ; 0,8$ a 2,8 e 3,8 a 5,8 ; para a pescada-polaca: 70,1 a 71,$3 ; 16,1$ a 17,$0 ; 6,6$ a 9,6 e 3,4 a 4,0 ; para as merluzas: 71,6 a 78,$0 ; 13,3$ a 15,$5 ; 0,3$ a 5,3 e 3,0 a 5,9 .

Segundo HESS (1956) as características naturais da carne de pescado podem variar segundo a estação do ano, as condições de desova, a idade e o local de captura que influem especialmente no teor de lípides da carne, no grau de saturação dos ácidos graxos presentes no peixe gordo e no sabor final da carne.

Em peixes de água doce, duas espécies de bagre (Wallago attu e Nacrones aor) e um Ciprinídeo (Barbus dubins), coletados mensalmente desde 1957 até 1960 e analisados por SREENIVASAN \& NATARAJAN (1961), os teores de umidade, proteína e lípides variaram com a espécie, dentro de cada espécie e com a época do ano. A umidade oscilou entre 72,60 e $84,83 \%$, as proteínas entre 14,88 e $19,26 \%$ e os lípides entre 0,21 e $7,20 \%$. 
THURSTON (1962) verificou as características físicas e a composição química de duas espécies de trutas habitantes de lagos. Nos filés da espécie mais magra, Cristivomer namaycush com peso médio de $1,62 \mathrm{~kg}$ encontrou $73,0 \%$ de umidade, $18,0 \%$ de proteína, $9,4 \%$ de lípides e $1,0 \%$ de cinza. Nos filés da espécie mais gorda, Cristivomer sisconset com peso médio de $3,70 \mathrm{~kg}$, encontrou $41,4 \%$ de umidade, $9,6 \%$ de prote ína, $48,5 \%$ de lípides e $0,6 \%$ de cinza. As análises foram feitas na parte comestível incluindo o depósito de gordura da parte ventral.

De acordo com um programa de pesquisa desenvolvido pelo "Department of Interior Fish and Wildlife Service" dos Estados Unidos (1951-1953), foi determinada a composição centesimal de várias espécies de peixe de água doce da América do Norte. Dentre as espécies analisadas estão: lúcio amarelo (Stizostedion vitreum), "sheepshead" (Aplodinotus grunniens), lúcio azulado (Stizostedion glaucum), perca amarela (Percha flavescens), "whitefish" (Coregonus clupeaformis), "smelt" (Osmerus mordax), "smelt" (Thaleichtys pacificus), "buffalofish" (Ictiobus sp.), carpa (Cyprinus carpio), "chub" (Leucichthys sp.), "bullhead" (Ameiurus melas), truta de lago (Cristivomer naraycush) e "squawfish" (Ptychocheilus grandis). Os teores máximos e mínimos em porcentagem, encontrados nos filés de vinte e seis peixes analisados foram: 84,60 e 64,30 para umidade; 19,38 e 0,56 para lípides; 20,30 e 13,80 para proteína e 1,43 e 0,83 para cinza.

LESSI (1965) determinou a composição centesimal do corimbatá (Prochilodus scrofa), peixe de água doce do rio Mioji-Guaçu, Estado de São Paulo e encontrou para o filé e para o peixe inteiro, respectivamente: 72,50 e $71,60 \%$ de umidade; 20,50 e $21,48 \%$ de proteína; 6,68 e $5,56 \%$ de extrato etéreo; 1,38 e $3,29 \%$ de cinza e 0,02 e $0,21 \%$ de fibras.

Estudando a composição centesimal de oito espécies de peixes da bacia do rio Moji-Guaçu, Estado de São Paulo, LESSI (1968), encontrou na parte comestivel do mandi-guaçu (Pimelodus clarias): 62,78\% de umidade, 18,25\% de proteína, 16,79\% de extrato etéreo e $1,57 \%$ de cinza. Dentre as outras espécies analisadas pelo autor o dourado (Salminus maxillosus) apresentou o teor de prote ína mais elevado:22,37\%.

CAMARGO et alii (1973) determinaram a umidade e os lípides de alguns peixes brasileiros, além das constantes físicas e químicas dos extratos etéreos. Os autores analisaram os peixes do rio Moji-Guaçu capturados no período entre junho e outubro, encontrando os resultados citados a seguir. A maior porcentagem de umidade ocorreu no corimbatá (Prochilodus scrofa) com 78,07\% e a menor porcentagem na mandiuva (Pimelodus clarias) com 64,03\%. A piapara (Leporinus piapara) com 72,88\%, o dourado (Salminus maxillosus) com $72,33 \%$ e a piava (Leporinus copelandi) com 70,88\%, apresentaram os teores intermediários de umidade. Os teores mais elevados de lípides foram os de mandiuva e da piava com $14,88 \%$ e $11,22 \%$, respectivamente. O dourado e a piapara apresentaram os teores intermediários, $6,49 \%$ e $6,18 \%$ e o menor teor encontrado foi o do corimbatá com $2,79 \%$ de lípides. 
MATERI AL E MÉTODOS

\section{Matéria-prima}

A matéria-prima, constituída de peixes conhecidos por mandi, foi adquirida de pescadores às margens do rio Piracicaba, no município de Piracicaba, Estado de São Paulo.

Segundo STORER \& USINGER (1971), os mandis pertencem à classe Osteichthyes, subclasse Actinopterygii, ordem Cypriniformes e família Siluridae. De acordo com GOMES \& MONTEIRO (1965) foram classificados como Pimelodus clarias por Bloch em 1795 e por Lacépède em 1803.

EIGENMANN \& EIGENMANN (1890), classificaram os mandis de alguns rios da América do Sul como pertencentes à espécie Pimelodus clarias. RIBEIRO (1918), classificou a espécie de mandi, predominante no rio Piracicaba, como Pimelodus clarias.

Os mandis são peixes de couro; seu comprimento varia entre 20 e $45 \mathrm{~cm}$ e sua massa de $100 \mathrm{~g}$ a $1 \mathrm{~kg}$, de acordo com mensurações feitas por MONTEIRO (1953). Os machos atingem $33 \mathrm{~cm}$ de comprimento e $550 \mathrm{~g}$, enquanto que as fêmeas alcançam $45 \mathrm{~cm}$ com cerca de $1 \mathrm{~kg}$, segundo citação de GOMES \& MONTEIRO (1965). No presente trabalho foram usados espécimes com 100 a $300 \mathrm{~g}$, recém-capturados.

\section{Métodos}

\section{Umidade}

Determinada por método gravimétrico, através da perda de massa por aquecimento a $105^{\circ} \mathrm{C}$ até massa constante, segundo LUDORFF (1963).

\section{Proteina}

Determinada pelo método de Kjeldahl, micro, segundo A.O.A.C. (1971).

\section{Lipides}

Determinados por método gravimétrico após extração por clorofórmio-metanol, de acordo com FOLCH et alii (1957).

\section{Cinza}

Determinada por método gravimétrico, através da perda de massa após incineração a 550C, segundo A.O.A.C. (1971).

\section{Amostragem}

As análises químicas dos mandis "in natura" foram feitas em amostras de 10 pєixes com massa de 100 a $300 \mathrm{~g}$. Depois da evisceração e lavagem em água corrente, foi retirada a parte comestível com um corte da cabeça à cauda, rente à coluna vertebral. Da parte comestível foram retiradas as nadadeiras e a carne foi homogeneizada em liquidificador a $1.500 \mathrm{rpm}$ por 2 minutos. 


\begin{tabular}{|c|c|c|c|c|c|c|c|c|}
\hline & & \multirow[b]{2}{*}{$\begin{array}{l}\text { Umidade } \\
\mathrm{g} / 100 \mathrm{~g})\end{array}$} & \multicolumn{2}{|c|}{ Proteína ${ }^{*}(\mathrm{~g} / 100 \mathrm{~g})$} & \multicolumn{2}{|c|}{ Lípides $(\mathrm{g} / 100 \mathrm{~g})$} & \multicolumn{2}{|c|}{ Cinza $(g / 100 g)$} \\
\hline & & & $\begin{array}{l}\text { Matéria } \\
\text { úmida }\end{array}$ & $\begin{array}{c}\text { Matéria } \\
\text { seca }\end{array}$ & $\begin{array}{l}\text { Matéria } \\
\text { úmida }\end{array}$ & $\begin{array}{l}\text { Matéria } \\
\text { seca }\end{array}$ & $\begin{array}{l}\text { Matéria } \\
\text { úmida }\end{array}$ & $\begin{array}{c}\text { Matéria } \\
\text { seca }\end{array}$ \\
\hline \multirow{12}{*}{ 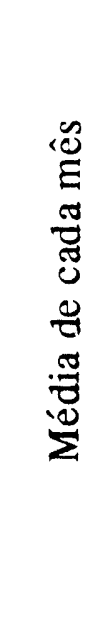 } & Janeiro & 59,31 & 18,21 & 44,75 & 21,10 & 51,85 & 1,57 & 3,86 \\
\hline & Fevereiro & 60,84 & 16,89 & 43,13 & 19,84 & 50,66 & 1,60 & 4,08 \\
\hline & Março & 64,56 & 17,24 & 48,64 & 16,45 & 46,42 & 1,57 & 4,43 \\
\hline & Abril & 63,48 & 19,36 & 53,01 & 15,50 & 42,44 & 1,03 & 2,82 \\
\hline & Maio & 73,31 & 16,65 & 62,38 & 10,12 & 37,92 & 0,90 & 3,37 \\
\hline & Jurho & 71,97 & 17.50 & 62,43 & 9,40 & 33,53 & 0,91 & 3,25 \\
\hline & Julho & 72,08 & 18,37 & 65,79 & 8,61 & 30,84 & 1,33 & 4,76 \\
\hline & Agosto & 68,02 & 17,80 & 55,66 & 12,67 & 39,62 & 1,51 & 4,72 \\
\hline & Setembro & 63,56 & 17,96 & 49,29 & 16,28 & 44,68 & 1,40 & 3,84 \\
\hline & Outubro & 63,40 & 16,69 & 45,60 & 18,70 & 51,09 & 1,51 & 4,12 \\
\hline & Novemb ro & 62,37 & 19,14 & 50,86 & 17,53 & 46,58 & 1,48 & 3,93 \\
\hline & Dezembro & 59,00 & 19,25 & 46,95 & 20,02 & 48,83 & 1,33 & 3,24 \\
\hline \multicolumn{2}{|c|}{ Média do ano } & 65,15 & 17,92 & & 15,51 & & 1,34 & \\
\hline \multicolumn{2}{|c|}{ Máximos (M) } & 74,55 & 19,36 & & 22,29 & & 1,63 & \\
\hline \multicolumn{2}{|c|}{ Mínimos (m) } & 57,75 & 16,54 & & 7,42 & & 0,87 & \\
\hline \multicolumn{2}{|l|}{$\mathrm{M} / \mathrm{m}$} & 1,29 & 1,17 & & 3,00 & & 1,67 & \\
\hline
\end{tabular}

* $\mathrm{N} \times 6,25$

TABELA 1 - Composição centesimal de mandis "in natura" recém-capturados, analisados mensalmente durante 12 meses 


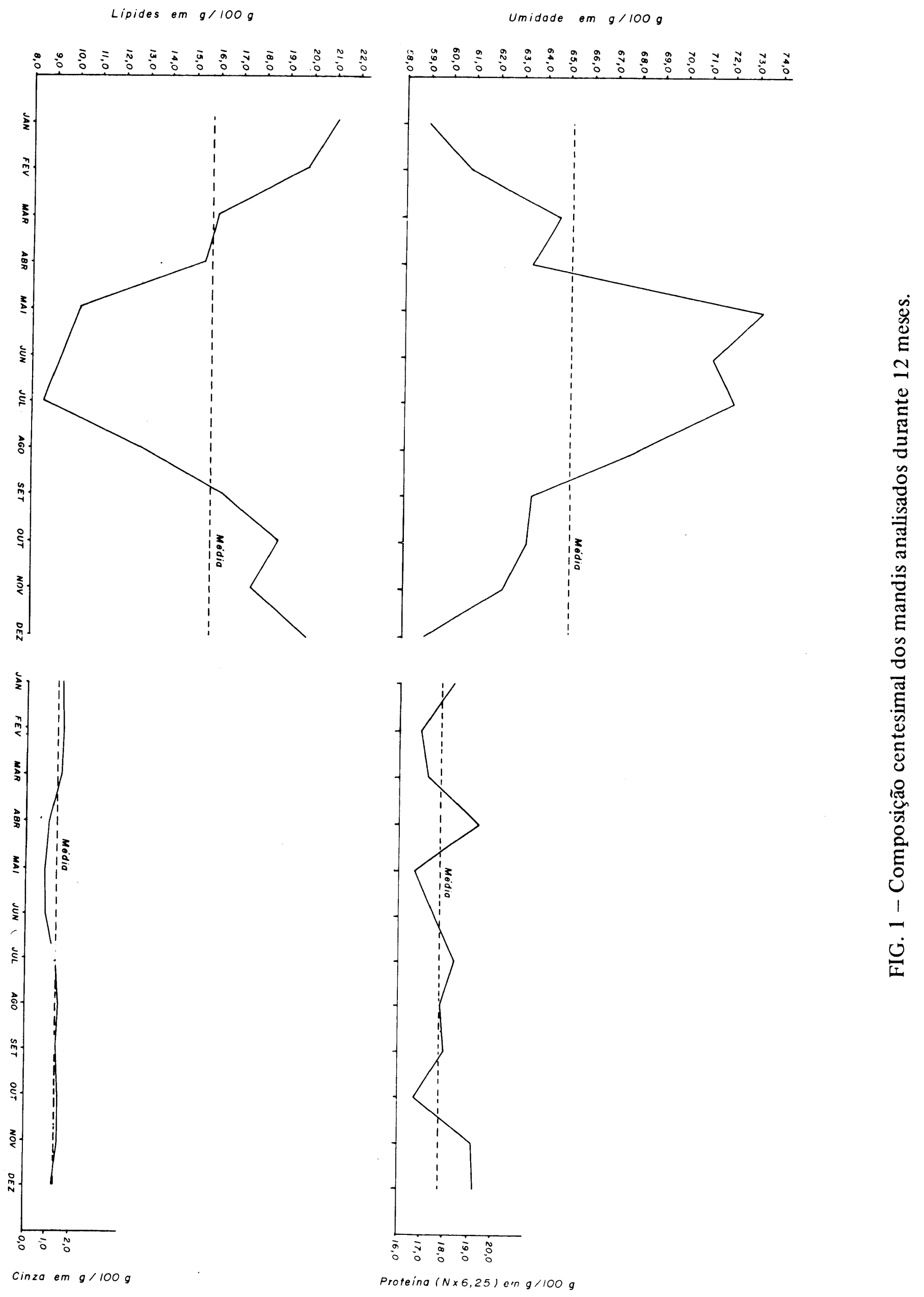




\section{DISCUSSÃO DOS RESULTADOS}

A composição centesimal representada na Tabela 1, e Figura 1, variou em função do mês. A umidade e os lípides variaram uniformemente atingindo um máximo e depois decrescendo. A cinza apresentou a mesma tendência, ao passo que a proteína variou de maneira desuniforme.

Os teores médios de umidade variaram entre 59,00 e $73,31 \mathrm{~g} / 100 \mathrm{~g}$. Os teores mais baixos foram encontrados nos meses de janeiro e dezembro, tendo havido um acréscimo até o mês de maio, quando se verificou o valor máximo. De maio a julho a umidade permaneceu nos valores mais altos, decrescendo progressivamente daí atél $\delta$ final do ano.

Os teores médios de lípides variaram entre 8,61 e $21,10 \mathrm{~g} / 100 \mathrm{~g}$. Os teores máximos foram encontrados em janeiro e dezembro. Após o mês de janeiro houve um decréscimo até os valores mínimos, de maio a junho, seguido de um acréscimo até dezembro.

Os teores médios de cinza oscilaram entre 0,90 e $1,60 \mathrm{~g} / 100 \mathrm{~g}$. Houve um pequeno acréscimo de janeiro a fevereiro, quando se notou o valor máximo seguido de um decréscimo até junho, com uma queda acentuada até abril e maio quando se verificou o valor mínimo.

Os teores médios de proteína variaram entre 16,65 e $19,36 \mathrm{~g} / 100 \mathrm{~g}$. Os resultados mais elevados (19,36 e 19,25 g/100 g) foram encontrados nos meses de abril e dezembro, respectivamente. Os menores valores $(16,65 ; 16,69$ e $16,89 \mathrm{~g} / 100 \mathrm{~g})$ foram encontrados nos meses de maio, outubro e fevereiro, respectivamente. Conseqüentemente, não se percebe uma progressiva alternância nos teores. Entretanto, em termos de matéria seca, discutidos adiante, ocorreram máximos hem definidos.

A variação da composição centesimal ocorre em função de vários fatores inerentes an próprio peixe e ligados ao meio ecológico. Diversos autores, como BROOKE (1962), DAMBERGS (1963), HESS (1956), JACQUOT (1961), LOVE (1957), LUDORFF (1963), MacCALLUM et alii (1969), NOTEVARP (1957), RULEV \& MAKAROVA (1959) e STANSBY (1951), chamam a atenção para a influência da espécie, tamanho, sexo, idade, estágio de maturação, estado de nutrição e partes do corpo do peixe, como também local de captura, disponibilidade alimentar e outras condições ambientais.

A variação nos teores de umidade na carne do mandi, no decorrer do ano, foi dependente da variação em lípides. Assim, quando os peixes possuem mais lípides, apresentam menos umidade e vice-versa. Esse mesmo comportamento com relaç̧ão a esses dois componentes foi verificado por CAMARGO (1973), FRONTIER ABOU (1970), JACQUOT (1961), MacCALLUM (1969) e RULEV \& MAKAROVA (1959).

Os teores de lípides, que alcançaram $22,29 \%$, permitem classificar o mandi na classe de peixes gordos, os quais, segundo JACQUOT (1961) incluem as espécies que apresentam no mínimo $10 \%$ de lípides.

A composição centesimal do mandi, encontrado neste trabaiho, está condizente com os resultados encontrados nas análises do "Department of Interior Fish and Wildlife Service" (1951-1953) e de alguns autores como LUDORFF (1963), NOTEVARP (1957), RULEV \& MAKAROVA (1959), THURSTON (1961) e WAGENKNECHT 
\& LANGECKER (1969), para outras espécies de peixes de mar e de rio. Da mesma forma é semelhante aos obtidos, no Brasil, por CAMARGO (1973) e LESSI (1968) em seus estudos sobre a composição centesimal do Pimelodus clarias. Entretanto, divergem dos teores de alguns componentes, principalmente dos lípides, citados por outros pesquisadores como BROOKE (1962), FERREIRA (1951), ITÓ \& WATANABE (1968), ITÔ et alii (1969), KHOBOTILOVA (1967), LESSI (1966) e THURSTON (1961).

Os teores de proteína foram citados em porcentagem de matéria seca, por GEIGER (1962), que explica ạ oscilaçẫo do teor de proteína em função das variações na umidade. No mandi, quando expressos em matéria seca, foram encontrados teores máximos de proteína nos meses de maio $(62,38 \mathrm{~g} / 100 \mathrm{~g})$, junho $(62,34 \mathrm{~g} / 100 \mathrm{~g})$ e julho $(65,79$ $\mathrm{g} / 100 \mathrm{~g})$, quando os teores de umidade são altos.

\section{CONCLUSÕES}

Os mandis "in natura", recém-capturados, do rio Piracicaba, com massa de 100 a $300 \mathrm{~g}$, analisados por doze meses, acusaram variação mensal da composição, com máximos e mínimos bem definidos.

A composição média dos mandis analisados durante um ano foi: $65,15 \mathrm{~g} / 100 \mathrm{~g}$ de umidade; $17,92 \mathrm{~g} / 100 \mathrm{~g}$ de proteína; $15,51 \mathrm{~g} / 100 \mathrm{~g}$ de lípides e $1,34 \mathrm{~g} / 100 \mathrm{~g}$ de cinza na parte comestivel.

Os teores máximos de umidade e os mtínimos de lípides, nos mandis, coincidiram nos meses de maio e junho; os teores mínimos de umidade e os máximos de lípides, coincidiram nos meses de janeiro e dezembro.

Os teores de proteína nos mandis variaram mensalmente de maneira desuniforme e não apresentaram máximos e mínimos definidos; porém, em termos de matéria seca, os peixes apresentaram máximos de proteína nos meses de maior umidade.

\section{SUMMARY}

\section{SEASONAL VARIATION OF THE CHEMICAL COMPOSITION OF BRAZILIAN FRESH WATER FISH Pimelodus clarias BLOCH (MANDI)}

This work was carried out on "mandi" (Pimelodus clarias Bloch) a specie of catfish from Piracicaba river in São Paulo State, Brazil, with the purpose of knowing the influence of the fishing season on moisture, protein, lipids and ash contents of fish flesh, to select the best time to make preserves.

The edible part of "mandi" was analysed monthly during a year and showed the following data: moisture $65.15 \mathrm{~g} / 100 \mathrm{~g}$, protein $17.92 \mathrm{~g} / 100 \mathrm{~g}$, lipids $15.51 \mathrm{~g} / 100 \mathrm{~g}$ and ash $1.34 \mathrm{~g} / 100 \mathrm{~g}$. The lipids data permitted to classify "mandi" as a fatty fish and june and july were the elected months to pick out fishes for processing. 


\section{LITERATURA CITADA}

ANDRADE, M.O., 1975. Preparo, seleção, armazenamento e estudos químicos e sensoriais de conservas de mandi, Pimelodus clarias Bloch. São Paulo, 127 p. Tese (mestrado). Faculdade de Ciências Farmacêuticas. Universidade de São Paulo.

ASSOCIATION OF OFFICIAL AGRICULTURAL CHEMISTS, 1971. Official and tentative methods of analysis. 11th. ed. Washington, A.O.A.C., p. 295, 526 and 858.

BROOKE, R.O. et alii, 1962. The composition of commercially important fish taken from New England waters. II: Proximate analysis of butterfish, flounder, pollock and hake, and their seasonal variation. J. Food Sci, Chicago, 27(1):73-6.

CAMARGO, L.A. de A., 1973. Constantes físicas e químicas dos extratos etéreos de alguns peixes brasileiros. Arch. Latinoamer. Nutr., Caracas, 23(1):135-44.

DAMBERGS, N., 1963. Extractives of fish muscle. III : Amounts sectional distribution, and variations of fat, water-solutes, protein and moisture in cod fillets. J. fish. Res. Bd. Canada, Ottawa, 20(4) $909-18$.

EIGENMANN, C.H. \& EIGENMANN, R.S., 1890. A revision of South American Nematognathi or cat fishes. Occ. Pap Cal. Acad. Sci., 1:1-509. Apud. GOMES, A.L. \& MONTEIRO, F.P. Estudo da população de peixes da represa da Estação Experimental de Biologia e Piscicultura em Pirassununga, SP. R. Biol. Mar., Valparaíso, 6(1/3):101. 1955.

EUA - Department of the interior fish and wildlife service. Composition of freshwater fish, 19511953. Commer. fish Rev., Seattle, 13(12):13-4, 1951; 14(1):17, (2):30, (3) :22, (4):15, (6): 21-2, (9):20, (10):27, (11):10, (12):15, 1952; 15(2):30, (4):17, (10):17-8, (12):14-5, 1953.

FERREIRA, F.A.G., 1951. Composição e valor alimentar de algumas espécies de peixe. B. Pesca, Lisboa, 8(33):89.

FOLCH, J. et alii., 1957. A simple method for the isolation and purification of total lipids from animal tissues. J. Biol. Chem., Baltim ore, $226: 497-509$.

FRASER, D.I. et alii., 1961. Proximate composition of Canadian Atlantic fish. III : Sectional differences in the fish of a species of Chondrostei, one of chimaerae and some miscellaneous teleosts. J. Fish Res. Bd. Canada, Ottawa, 18(6) 893-905.

FRONTIER-ABOU, D., 1970. Composición del tejido muscular de algunos peces de la Costa Malagasy. Cah. O.R.S.T.O.M. Scr. Oceanogr., Paris, 7(1):3-18, 1969. Apud. Wld. Fish Abstr., Es., 21(2) 21.

GEIGER, E., 1962. Fish protein-nutritive aspects In: BORGSTROM, G. ed. - Fish as food, New York, Academic Press, v.2, p. 32, 35, 37-8.

GOMES, A.L. \& MONTEIRO, F.P., 1965. Estudo da população total de peixes da represa da Estação Experimental de Biologia e Piscicultura em Pirassununga, SP. Rev. Biol. Mar., Valparaíso, 6(1/3):101, 124.

GRISHINA, N.L. \& KUZNETSOV, D.I., 1974. Rapid extraction gravimetric method for the determination of lipids in fish and fish products (em russo). Ryb. Khoz, Moscou, 4.67-8.

HESS, E., 1956. Problemas tecnológicos actuales de la conserveria de pescado. B. Pesca FAO, Roma, 9(4):180, 192 e 193.

ITÔ, Y. \& WATANABE, K., 1968. Variations in chemical composition in the fillet of corvina and "pescada-foguete". Contr. Inst. Ocean. Un. São Paulo, série Tecnol., 5 :1-6.

ITŌ, Y. et alii., 1969. Seasonal variation of the chemical composition of sardine. Contr. Inst. Ocean. Un. São Paulo, série Technol., 6:1-8.

JACQUOT, R., 1961. Organic constituents of fish and other aquatic foods. In: BORGSTROM, G., ed. - Fish as food. New York, Academic Press, v.1, p. 146-50. 
KHOBOTILOVA, L.D., 1967. Weight and chemical composition of sea perch and flounders (em russo). Ryb. Khoz. Okeanogr., Moscou, 22:110-26.

LESSI, F., 1965. Aspectos químico-bromatológicos do corimbatá (Prochilodus scrofa). Araraquara, 44 p. Tese (doutoramento), F.F.O.

LESSI, E., 1968. Determinação da composição centesimal e da identificação dos aminoácidos da fração protéica de alguns peixes da bacia do rio Moji-Guaçu, SP. Rev. Soc. Farm. Odont. Araraquara, 2(2):197-203.

LOVE, R.M., 1957. The biochemical composition of fish. In: BROWN, M.E. The physiology of fishes. New York, Academic Press, v.1, p. 401-15.

LOVERN, J.A., 1965. Some analytical probiems in the analysis of fish and fish products J.A.O.A.C., Washington, 48(1).60-8.

LUDORFF, W., 1963. El pescado y sus productos. (Trad.) Zaragoza, Acríbia. p. 34-5, 108, 117-8, $139,157,159$.

MacCALLUM, W.A. et alii., 1969. New foundland capelin proximate composition. J. Fish Res. Bd. Canada, Ottawa, 26(8):2027-35.

MONTEIRO, F.P., 1953. A pesca no rio Piracicaba. Piracicaba, 76 p. Tese (doutoramento) ESALQ.

NOTEVARP, O., 1957. Herring - the raw material. Fishing News, Londres, 17-9, 1950

RIBEIRO, A. de M., 1918. Peixes. Rev. Museu Paulista, 10:730, 1918. Apud FOWLER, H.W. Os peixes de água doce do Brasil. Arq. Zool. Est. São Paulo, 6 556, 1951.

RULEV, N.N. \& MAKAROVA, A.P., 1959. Technical and chemical characteristics of the Atlantic herring as industrial raw material (em russo). Ryb. Khoz., Moscou, 35(3) 51 -4.

SREENIVASAN, A. \& NATARAJAN, M.V., 1961. Variations in the chemical composition of three freshwater fishes of Bhavanisagar reservoir. Ind. J. Fish, Bhavanisagar, 8(2):436-9.

STANSBY, M.E., 1951. Fish, shellfish and crustacea. In: JACOBS, M.B. - The chemistry and technology of food and food products. 2nd. ed. New York, Interscience, v.2, p. 943-4.

STORER, T.I. \& USINGER, R.L., 1971. Zoologia geral. São Paulo, Ed. USP, p. 564-84.

THURSTON, C.E., 1961. Proximate composition and sodium and potassium contents of four species of commercial bottorn ish. J. Food. Sci., Chicago. 26(5):495-8.

THURSTON, C.E., 1962. Physkai characteristics and chemical composition of two subspecies of lake trout. J. Fish. Res. Bd. Canada, Ottawa, 19:39-44.

WAGENKNECHT, W. \& LANGECKER, L., 1969. Composition and properties of West Africa edible fishes. Lebensm. Ind., Marienche, 16(8):306-8. 
